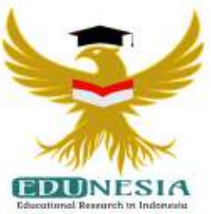

\title{
Pengembangan Pkn Di Era Generasi Millenial Berbantuan M-Learning (Mobile Learning) Pada Gadget Pembelajaran Berbasis Cooperative Learning Bermuatan Karakter
}

\author{
Feri Wagiono', Syahrial Shaddiq2, Aulia Akhrian Syahidi ${ }^{3}$ \\ ${ }^{1}$ Pendidikan PPKn, Universitas Palangka Raya (UPR) Palangka Raya, Indonesia \\ 2 Ilmu Ekonomi (Manajemen SDM), Universitas Islam Indonesia (UII) Yogyakarta, Indonesia \\ ${ }^{3}$ Teknik Informatika, Politeknik Negeri Banjarmasin (POLIBAN), Indonesia \\ ${ }^{1}$ Corresponding Email: wagionoferi456@gmail.com, Phone Number :0812 xxxx xxxx
}

\author{
Article History: \\ Received: Juli 31, 2020 \\ Revised: Agust 03, 2020 \\ Accepted: Agust 03, 2020 \\ Published: Nov 01, 2020
}

Keywords:

Millennials, cooperative learning of character-laden, media of gadget, $\mathrm{M}$ Learning

Kata Kunci:

Generasi millenial, cooperative learning bermuatan karakter, media gadget, M-Learning

How to cite:

Wagiono, F., Shaddiq, S. \& Syahidi, A.A. (2020) Pengembangan PKn Di Era Generasi Millenial Berbantuan M-Learning (Mobile Learning) Pada Gadget Pembelajaran Berbasis Cooperative Learning Bermuatan Karakter. Edunesia : Jurnal Ilmiah Pendidikan, 1 (3) 63-72

This is an open access article under the CC-BY-NC-ND license (c) $(1) \$$
Abstract: Study of the phenomenon of globalization spawned the cultural generation gadget, the term emergence of the millennial generation, or Generation $Y$ aged 15-34 years. Technology utilization in youth to disseminate negative content such as violence, Asusila, conflict, and hoaxes. The Moral and deviant behavior of youth becomes a threat to Indonesia. The purpose of this article is the development of a millennial-generation PKn (citizenship education) curriculum for students SMA NU Palangka Raya. with a gadgetassisted Cooperative Learning Model. Research is approaches qualitative. The research subject consists of the principal, teacher, and students SMA NU Palangka Raya. Data Collection techniques in research using interview techniques, observations, and documentation. Development of a millennialGeneration PKn curriculum with models Cooperative Learning more effective assisted M-Learning (Mobile Learning) on gadgets makes a video or Indonesian film courses in PKn. Students can work together in groups to learn and be responsible for learning success. Hopefully, This model can help teachers in overcoming the condition of the students who have different abilities, the number of students, and solid learning. Students do not get bored quickly because they watch videos or the Indonesian movie with character.

Abstrak: Studi tentang fenomena globalisasi melahirkan generasi budaya gadget, istilah munculnya generasi millenial atau generasi $\mathrm{Y}$ berusia 15-34 tahun. Pemanfaatan teknologi pada pemuda untuk menyebarkan konten negatif seperti kekerasan, asusila, konflik dan hoax. Moral dan perilaku menyimpang pemuda menjadi ancaman bagi Indonesia. Tujuan artikel ini ialah pengembangan kurikulum PKn (Pendidikan Kewarganegaraan) generasi millenal pada siswa SMA NU Palangka Raya berbantuan gadget dengan model cooperative learning bermuatan karakter. Penelitian ini adalah pendekatan kualitatif. Subjek penelitian terdiri dari kepala sekolah, guru dan siswa SMA NU Palangka Raya. Teknik pengumpulan data dalam penelitian menggunakan teknik wawancara, observasi, dan dokumentasi. Pengembangan kurikulum PKn generasi millenial dengan model cooperative learning lebih efektif berbantuan M-Learning (Mobile Learning) pada gadget membuat video atau film keindonesiaan mata pelajaran PKn. Siswa dapat bekerja sama dalam kelompok untuk belajar dan bertanggung jawab akan keberhasilan belajar. Diharapkan model ini dapat membantu guru dalam mengatasi kondisi siswa memiliki kemampuan berbeda, jumlah siswa banyak dan padatnya pembelajaran. Siswa tidak cepat bosan karena menonton video atau film keindonesiaan berkarakter. 


\section{A. Pendahuluan}

Generasi Millenial merupakan terminologi generasi yang saat ini banyak diperbincangkan oleh banyak kalangan. Siapa sih generasi millenial itu? Generasi Millenial sering disebut sebagai Generasi Y. Seorang peneliti sosial mengelompokkan generasi millenial yang lahir antara tahun 1980 an sampai 2000 an. Jadi bisa dikatakan generasi millenial adalah generasi muda masa kini yang berusia 15-34 tahun (Zuhal, 2000).

Indonesia adalah negara berkembang. Fenomena menarik saat ini arus globalisasi budaya global (global culture) negara-negara maju (Barat) telah mendominasi dan bahkan menghegemoni negara-negara terbelakang, atau bangsa yang masih berkembang seperti di Indonesia. Globalisasi sering dianggap sebagai proses mendunia dari sistem sosialekonomi-politik dan budaya, sering kita jumpai maraknya pemuda yang menyukai gaya hidup (lifestyle) kebarat-baratan, budaya pop/ musik dan hiburan (entertainment) menjadi kebutuhan pokok tak bisa dibendung lagi.

Salah satu fenomena penting proses globalisasi saat ini telah melahirkan generasi budaya gadget, istilah yang digunakan untuk menandai munculnya generasi millenial. Gadget sebenarnya lebih pas diartikan dengan peralatan, sehingga generasi gadget dimaksudkan dengan generasi yang dalam kehidupannya selalu bersinggungan dengan yang namanya peralatan yang mengandung unsur teknologi informasi. Jadi seolah-olah berbagai peralatan tersebut telah menjadi bagian yang tak terpisahkan dari kehidupan mereka (Cao, Y. dkk., 2019). Seolah-olah berbagai alat high-technology telah menjadi bagian penting dalam kehidupannya (Petrova, A., \& Podzygun, 2018; Naisbitt, 2002).

Menurut Emi (2015), Sejumlah penelitian tentang dampak dan pemanfaatan internet menunjukkan bahwa internet menjadi sumber utama belajar tentang apa yang terjadi di dunia seperti untuk hiburan, bergembira, relaksasi, untuk melupakan masalah, menghilangkan kesepian, untuk mengisi waktu sebagai kebiasaan dan melakukan sesuatu dengan teman dan keluarga. Banyak manfaat yang diperoleh dari internet, terutama dalam proses komunikasi dan penggalian informasi bagi seluruh masyarakat pengguna internet termasuk remaja (Emi, 2015). Internet dapat dengan cepat mendapatkan informasi, bisa mencarinya menggunakan google atau dengan cara yang lain, tetapi kebanyakan remaja menggunakan internet untuk mencari teman, chatting, kirim email, atau mencari tugas-tugas kuliah atau tugas sekolah. Di kalangan remaja masa kini yang lagi marak-maraknya adalah friendster, Facebook, Twitter. Mereka mencari teman melalui friendster maupun facebook dan juga bisa kirim-kirim foto atau dan lain sebagainya (Savarin, W.J and Tankard, 2005).

Akhir-akhir ini maraknya anak muda yang rendah atau bahkan tidak memiliki kesadaran akan nilai-nilai kesopanan dan kesantunan terhadap orang yang lebih tua. Pemanfaatan teknologi untuk menyebarkan konten-konten yang bersifat negatif seperti mengandung unsur kekerasan, asusila, memancing konflik, hoax (kebohongan), bawa kendaraan tidak mengenakan standar keselamatan dan membawa surat-surat mengemudi.

Di kalangan remaja Indonesia saat ini, pemanfaatan teknologi itu sendiri pada akhirnya menggerus nilai-nilai yang seharusnya diterapkan ketika hendak bersilaturahmi seperti pada saat berkumpul, bertemu dan bertatap muka lebih mementingkan bermain gadget dan lain-lain, serta senang berkata-kata kasar di sosial media dan lain sebagainya hingga berujung konflik. Fenomena terkait aktifitas generasi muda yang tidak terkendali justru membentuk karakter negatif seperti individualis, sombong, memandang rendah potensi orang lain, kurang menghormati perbedaan dan sebagainya.

Kecenderungan generasi millenial dalam penggunaan internet sering mengesampingkan moral dan etika. Padahal dalam tatanan sosial, etika sangat diperlukan guna menghindari terjadinya pergesekan konflik. Hal demikian, apabila tidak segera 
ditanggulangi maka di khawatirkan pada rusaknya etika dan moralitas generasi muda/ warga negara muda. Saat ini menurunnya moral dan sikap perilaku pemuda menjadi momok yang menakutkan bagi negara Indonesia. Generasi millenial inilah yang nantinya akan memegang tongkat estafet kepemimpinan. Apabila ini terus dibiarkan akan menjadi sebuah ancaman nyata yang mengakibatkan hancurnya sebuah negara karena tidak bermoralnya pemuda.

Wiedarti (2016), mengatakan semakin merosotnya moral para pelajar merupakan salah satu akibat dari pesatnya perkembangan teknologi yang tidak diimbangi dengan peningkatan kualitas budi pekerti pelajar, padahal perkembangan teknologi sangat dibutuhkan bangsa ini untuk dapat bersaing di era globalisasi. Kemerosotan moral banyak dipengaruhi oleh kondisi sosial-budaya dalam masyarakat sekitarnya. Lingkungan sosial yang buruk adalah bentuk dari kurangnya pranata sosial dalam mengendalikan perubahan sosial yang negatif (Wiedarti, 2016).

Di era saat ini membangun kepribadian pemuda yang mumpuni yaitu melewati pendidikan. Pendidikan menjadi solusi terbaik membangun jati diri seseorang. Jalan terbaik membangun negara adalah pendidikan. Sebab pendidikan sebagai jalan terbaik untuk membangun budaya masyarakat. Elemen pendidikan ada tiga yaitu membangun pengetahuan, keterampilan (skill) dan karakter. Dari ketiga elemen Pendidikan tersebut harus secara bersamaan dimiliki oleh jati diri seorang pemuda millenial.

Undang-undang Nomor 20 Tahun 2003 tentang Sistem Pendidikan Nasional menyebutkan bahwa kurikulum adalah seperangkat rencana dan pengaturan mengenai tujuan, isi, dan bahan pelajaran serta cara yang digunakan sebagai pedoman penyelenggaraan kegiatan pembelajaran untuk mencapai tujuan pendidikan tertentu. Berdasarkan pengertian tersebut ada dua dimensi kurikulum yang pertama adalah rencana dan pengaturan mengenai tujuan, isi, dan bahan pelajaran, sedangkan yang kedua adalah cara yang digunakan untuk kegiatan pembelajaran (Kemendikbud, 2016).

Di era global saat ini, banyak siswa kurangnya dalam kerjasama satu sama lain. Tak sedikit siswa merasa malu dan enggan bertanya kepada guru ketika kurang paham terkait materi yang disampaikan. Diskusi dalam kelas yang menonjol dan aktif adalah hanya beberapa siswa yang notabene nya berakademik lumayan bagus, siswa lain terkesan hanya jadi penonton dan diam terpaku. Pengajar hendaknya bisa menciptakan kondisi yang mana siswa harus bisa bekerjasama dengan siswa lain. Dengan demikian diperlukan kerjasama antara siswa dengan lainnya dalam menyelesaikan masalah materi pelajaran yang belum dikuasai, menyelesaikan tugas dan mengerjakan sesuatu untuk tujuan bersama (Trimurtini, 2009). Sehingga tercapai pembelajaran sesuai yang diharapkan.

Model cooperative learning, adalah strategi belajar mengajar dengan jalan mengelompokkan mahasiswa/ peserta didik berdasarkan tingkat kemampuannya pada kelompok yang kecil. Pada cooperative learning, keberhasilan peserta didik akan tercapai jika dan hanya jika setiap anggota kelompoknya berhasil (Farkas, 2015).

Pengembangan kurikulum adalah proses perencanaan kurikulum agar menghasilkan rencana kurikulum yang luas dan spesifik (Dryden, G \& Vos, 2001). Proses ini berhubungan dengan seleksi dan pengorganisasian berbagai komponen situasi belajarmengajar antara lain penetapan jadwal pengorganisasian kurikulum dan spesifikasi tujuan yang disarankan, mata pelajaran, kegiatan, sumber dan alat pengukur pengembangan kurikulum yang mengacu pada kreasi sumber-sumber unit, rencana unit, dan garis pelajaran kurikulum ganda lainnya, untuk memudahkan proses belajar mengajar (Farkas, 2015). Pada dasarnya pengembangan kurikulum ialah mengarahkan kurikulum sekarang ke tujuan pendidikan yang diharapkan karena adanya berbagai pengaruh yang sifatnya positif yang datangnya dari luar atau dari dalam sendiri, dengan harapan agar siswa dapat menghadapi masa depan dengan baik (Ioannou-Georgiou, 2011). 
Upaya Pendidikan Kewarganegaraan (PKn) untuk generasi millenial perlu diberdayakan di kehidupan sehari-hari. Hal demikian untuk meningkatkan kualitas budi pekerti warga negara muda. Dalam hal budaya sopan dan santun, menghargai proses, dan daya juang yang harus senantiasa dibiasakan dan dibinakan. Bertujuan mempersiapkan warga negara muda yang cerdas dan baik dapat di andalkan oleh bangsa dan negara untuk mengisi kemerdekaan dengan partisipasi yang positif dan efektif guna menyongsong masa depan lebih baik. Sehingga tercipta generasi muda yang berkualitas luhur dan berkarakter untuk Indonesia lebih baik.

Pendidikan Kewarganegaraan (PKn) memiliki tujuan mendidik warga negara yang baik, yang dapat dilukiskan dengan "warga negara yang: patriotik, toleran, loyal terhadap bangsa dan negara, beragama, demokratis ...... Pancasila sejati" (Wahana, 2015). Pendidikan Kewarganegaraan adalah sarana untuk membekali peserta didik dengan pengetahuan dan kemampuan dasar berkenaan dengan hubungan antar warga negara dengan negara serta pendidikan pendahuluan bela negara agar menjadi warga negara yang dapat di andalkan oleh bangsa dan negara (Wuryan dan Syaifullah, 2008).

Wahab (2011) menegaskan bahwa ruang lingkup Pendidikan Kewarganegaraan meliputi politik, hukum, pemerintahan, dan nilai serta moral yang berlandaskan pada Pancasila dan UUD NRI Tahun 1945. Dengan demikian, Pendidikan Kewarganegaraan mesti dipersiapkan dengan tepat dan cermat komposisi materi dan bahan-bahan penunjang pembelajarannya oleh para praktisi PKn agar dapat secara efektif dan efisien menumbuhkan karakter warga negara yang cerdas dan baik (Wahab dan Sapriya, 2011).

Berdasarkan fakta-fakta dan uraian peneliti diatas menunjukkan bahwa generasi millenial dalam kehidupannya tak terlepas dari media digital (gadget) dan teknologi informasi sebagai gaya hidup (lifestyle). Masalah yang dikemukakan penulis yaitu bagaimana media digital (gadget) dapat bermanfaat dalam pengembangan kurikulum PKn di era budaya generasi millenial pada model cooperative learning bermuatan karakter.

Zaman millenial ini mulai muncul istilah M-Learning. M-Learning adalah suatu bentuk atau model pembelajaran yang memanfaatkan kemampuan perangkat mobile. $M$ Learning mencakup banyak fitur electronic based learning/electronic learning (E-Learning) seperti konten multimedia dan komunikasi dengan siswa, hanya saja memiliki keunikan yaitu dalam hal fleksibilitas waktu dan tempat (Cheon, J. dkk., 2012). Perangkat mobile memiliki karakteristik seperti (1) portabilitas: dapat dibawa ke lokasi yang berbeda, (2) konektivitas cepat: dapat digunakan untuk mengakses berbagai informasi kapan dan dimana saja, dan (3) sensitivitas konteks: dapat digunakan untuk mencari dan mengumpulkan data nyata atau simulasi (Katz, 2012).

Tujuan pembuatan artikel ilmiah ini adalah untuk menerapkan, mengembangkan, dan menyampaikan tentang pentingnya pengembangan PKn di era millenial berbantuan M-Learning pada gadget model cooperative learning bermuatan karakter. Selain itu dengan penggunaan media digital (gadget) secara optimal sangat dirasakan kebermanfaatannya bagi pelajar daripada hanya digunakan untuk bermain game video dan virtual game lainnya.

\section{B. Metode}

Penelitian ini adalah kualitatif. Ini berdasarkan jenis data penelitian dalam bentuk data kualitatif. Penelitian ini memiliki subjek penelitian yaitu kepala sekolah, guru, dan siswa SMA NU Palangka Raya. Subjek penelitian merupakan sumber utama data penelitian, yang memiliki data pada variabel yang diteliti (Moser \& Korstjens, 2018). Penelitian data adalah informasi tentang penerapan pembelajaran pengembangan kurikulum PKn (Pendidikan Kewarganegaraan) generasi millennial berbantuan gadget dengan model cooperative learning di SMA NU Palangka Raya. Sumber data penelitian dikelompokkan menjadi dua jenis, informan dan dokumentasi. Informan terdiri dari 
kepala sekolah, guru yang mengajar siswa, dan siswa SMA NU Palangka Raya. Dokumentasi penerapan pembelajaran pengembangan kurikulum PKn (Pendidikan Kewarganegaraan) generasi millennial berbantuan gadget dengan model cooperative learning di SMA NU Palangka Raya.

Pengumpulan data dalam penelitian ini menggunakan wawancara, observasi dan dokumentasi. Informan yang diwawancarai adalah kepala sekolah, guru yang mengajar siswa, dan siswa SMA NU Palangka Raya yang belajar dengan gadget. Teknik wawancara digunakan untuk untuk mengeksplorasi data tentang pembelajaran Pendidikan Kewarganegaraan (PKn) di SMA NU Palangka Raya. Interview secara mendalam kepada Kepala sekolah, guru dan siswa kelas A dan B SMA NU Palangka Raya. Pengamatan dilakukan pada bentuk kesiapan guru dalam pembelajaran PKn siswa di SMA NU Palangka Raya. Dokumentasi dalam bentuk laporan penelitian tentang jurnal harian pembelajaran siswa penerapan pembelajaran pengembangan kurikulum PKn (Pendidikan Kewarganegaraan) generasi millennial berbantuan gadget dengan model cooperative learning di SMA NU Palangka Raya. Validitas data dalam penelitian ini menggunakan triangulasi. Menurut (Lion, 2013) membedakan triangulasi yaitu seperti triangulasi sumber, penyelidik dan teknik triangulasi dalam penelitian ini adalah triangulasi sumber dan teknik.Teknik analisis data dilakukan dalam beberapa tahap; yaitu reduksi data, pengumpulan data, penyajian data dan penarikan kesimpulan atau verifikasi.

\section{Hasil dan Pembahasan}

\section{Generasi Millenial dan Baby Boomer}

Akhir tahun 2016, Ipsos MORI, perusahaan konsultan, melakukan survei tentang persepsi atas dua generasi ini. Sebanyak 18.810 responden berusia di atas 16 tahun yang tersebar di 23 negara ditanyai pendapatnya tentang dua generasi ini. Hasilnya dalam pandangan masyarakat, citra atas dua generasi ini bertolak belakang. Baby boomer memiliki segala karakteristik dan perilaku yang positif. Sebanyak $47 \%$ responden mengatakan baby boomer adalah generasi yang sopan. Mereka juga menilaibaby boomer sebagai generasi pekerja keras, berpendidikan tinggi, beretika, dan peduli pada masyarakat sekitarnya.

Sementara millenial mendapatkan pandangan yang berkebalikan. Sebanyak 54\% responden setuju bahwa millenial adalah penggila teknologi. Sekitar $45 \%$ menilai mereka materialistik, 39\% menganggap para milenial egois, 34\% responden menyatakan milenial adalah generasi pemalas, dan 33\% menganggap mereka sombong. Laporan Time pada 2013 mendukung persepsi buruk atas generasi millenial tersebut sebagai hal yang memang benar. Ditulis oleh Joel Stein, laporan itu menyatakan millenial hanya memikirkan eksistensi diri sendiri, tak mau berusaha, dan bergantung pada teknologi (Zuhra, 2017). 


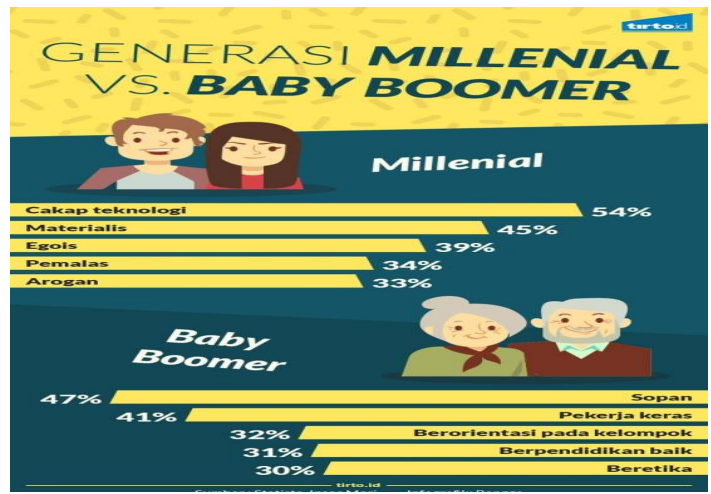

Gambar 1.

Generasi Millenial Vs. Baby Boomer

Sumber: Statista, Ipsos MORI (Infografik: Rangga)

\section{Objek Kajian Pendidikan Kewarganegaraan (PKn)}

Dalam menyusun bahan, strategi dan bentuk evaluasi pembelajaran Pendidikan Kewarganegaraan hendaknya memperhatikan objek kajian dari Pendidikan Kewarganegaraan. Objek kajian Pendidikan Kewarganegaraan itu sendiri dalam Buku CIVICS "Ilmu Kewarganegaraan" yang meliputi tingkah laku warga negara, tipe pertumbuhan berpikir, potensi setiap diri warga negara, hak dan kewajiban, cita-cita dan aspirasi, kesadaran (patriotisme, nasionalisme) dan usaha, kegiatan, partisipasi dan tanggung jawab warga negara (Ihsan, 2015). Dengan demikian bahwa civics bukan hanya mengajarkan pasal-pasal UUD, melainkan juga harus mencerminkan pula hubungan perilaku warga negara dalam kehidupannya sehari-hari dengan manusia lain dan alam sekitarnya. Oleh sebab itu, peran guru dalam mengajar dan membelajarkan Pendidikan Kewarganegaraan kepada warga negara muda menjadi titik krusial yang mesti mendapatkan perhatian dalam hal ini (Wahab dan Sapriya, 2011).

\section{Model Pembelajaran Berbasis Cooperative Learning Bermuatan Karakter Berbantuan Gadget dalam Pendidikan Kewarganegaraan (PKn)}

Menurut Tapscott (2013) dalam Growing Up Digital, kita adalah generasi pertama yang dikepung oleh media digital (Tapscott, 2013). Oleh karena itu, perlu dirancang pembelajaran dengan memanfaatkan media digital (gadget) (Simonson, 2016).

Saat ini kita tengah memasuki era digital. Kemunculan jaringan internet sebagai media informasi dan komunikasi mempengaruhi seluruh aspek kehidupan di dalam masyarakat. Pengaruh ini tidak hanya terjadi dalam kehidupan sosial, akan tetapi juga di dunia pendidikan (Wahana, 2015). Menurut Hasanudin (2014), generasi muda Indonesia sebagai pengguna internet penduduk kelompok usia 15-34 tahun atau 34,45\% jauh lebih tinggi dibanding dengan kelompok penduduk yang usianya lebih tua. Hal ini menunjukkan ketergantungan mereka terhadap koneksi internet sangat tinggi (Hasanudin, 2014).

Falsafah dasar pembelajaran cooperative learning adalah homo homini socius, bahwa manusia adalah makhluk social (Suyadi, 2015). Dalam konteks keindonesiaan, falsafah ini mirip dengan falsafah "Gotong-royong" atau kerja sama (Lestari, 2016). Demikian falsafah dasar pembelajaran cooperative learning mirip dengan filsafat pancasila yaitu gotongroyong. Model pembelajaran ini adalah belajar kelompok. Pandangan kelompok belajar disini ialah rangkaian belajar dilakukan oleh peserta didik dalam kelompok-kelompok untuk mencapai tujuan pembelajaran tertentu. Nilai-Nilai Karakter dalam Cooperative 
Learning terdiri dari (1) Kepedulian sosial; (2) Tanggung jawab; (3) Toleransi; (4) Kerja keras/ belajar keras, (5) Cinta tanah air dan semangat kebangsaan; (6) Bersahabat dan komunikatif; dan (7) Cinta damai. Penggunaan media gadget untuk memvideo/ membuat film oleh siswa cukup efektif merupakan terobosan baru bagi para pendidik untuk berkomunikasi dengan siswa dan orang tua siswa dalam menyediakan layanan informasi yang berhubungan dengan program pembelajaran sekolah (Marttila, 2017). Guru adalah pelukis masa depan dan arsitek peradaban. Lalu guru manakah yang patut mendapat penghormatan dan kemuliaan itu? Tentu, mereka adalah guru sejati (informan YK, wawancara 2 Januari 2020). Itulah guru yang beriman, cerdas, berkarakter dan berhati mulia. Mereka tampil sebagai guru profesional, jadi teladan, memberi inspirasi, mencerdaskan dan mencerahkan serta mengantarkan peserta didiknya. Sebab guru menjadi orang yang digugu dan ditiru (Saefulloh, 2018).

Pokok Bahasan Penerapan Cooperative Learning terdiri dari (1) Penjelasan Materi, Guru menjelaskan pokok materi pelajaran terlebih dahulu secara menyeluruh dan disesuaikan bahan ajar. Menggunakan metode ceramah. Tujuannya adalah agar peserta didik paham akan tugas-tugasnya. Diharapkan guru dapat menanamkan nilai karakter seperti tanggung jawab dan belajar keras atau bekerja dengan sungguh-sunguh pada siswa; (2) Media Pembelajaran, Sarana berfungsi mempresentasikan video atau film khas keindonesiaan seperti gotong-royong, demokrasi, persatuan dan kesatuan, perlindungan HAM sebagai warga negara, globalisasi di lingkungannya dan lain-lain yang nantinya dikumpulkan dalam bentuk file untuk dipresentasikan. Media yang digunakan LCD proyektor untuk mempresentasikan hasil kelompok dan media digital (gadget) merekam gambar; (3) Belajar dalam kelompok, Pembentukan kelompok yang heterogen terdiri 5-6 orang baik kemampuan akademik, skill, perbedaan gender, suku, ras, agama, dan sebagainya. Diharapkan dapat menanamkan nilai karakter seperti toleransi, cinta damai, bersahabat, komunikatif, kepedulian sosial, belajar keras dan sebagainya; (4) Penilaian/ Evaluasi, Penilaiannya lebih menekankan pada tes tanya jawab, peserta didik akan terlatih untuk berpikir dan tidak terpacu pada hafalan. Guru bisa melakukan tes individu atau kelompok. Tes individu memberi informasi kemampuan per individu, sedangkan tes kelompok memberi informasi kemampuan kelompoknya. Hasil akhir penilaian adalah akumulasi keduanya dijumlahkan bagi dua. Diharapkan guru menerapkan nilai karakter kejujuran, keadilan, tanggung jawab dan sebagainya (informan NK, wawancara 1 Januari 2020).

Langkah-langkah Menerapkan Model Pembelajaran Berbasis Cooperative Learning Bermuatan Karakter Berbantuan M-Learning (Mobile Learning) pada Gadget dalam Materi Pelajaran PKn Siswa SMA NU Palangka Raya

Langkah-langkah Menerapkan Model Pembelajaran Berbasis Cooperative Learning Bermuatan Karakter Berbantuan M-Learning (Mobile Learning) pada gadget dalam materi pelajaran PKn siswa SMA NU Palangka Raya terdiri dari kelas A dan kelas B: (1) Peserta didik pada kelas A dibagi menjadi kelompok-kelompok kecil 5-6 orang dengan kemampuan heterogen; (2) Tiap kelompok pada kelas A diberi tugas untuk membuat video atau film bertema keindonesiaan (gotong-royong, demokrasi, persatuan dan kesatuan, perlindungan HAM, globalisasi dan sebagainya) dengan media digital (gadget) yang dimiliki; (3) Masing-masing kelompok pada kelas A membuat ringkasan tentang sub bahasan yang dipelajari disesuaikan dengan video/ film yang dibuat. Untuk bahan diskusi dipresentasikan mapel PKn selanjutnya pada kelas lain yakni kelas B; (4) Pada 
kelas B yang tugasnya hanya mendownload aplikasi M-Learning yang mana di dalam konten M-Learning sudah ada video yang dibuat oleh para siswa kelas A, tugas kelas B hanya menggunakan dan belajar dengan M-Learning. (4) Kelas B diberikan kesempatan untuk menganalisis mengenai apa dan bagaimana isi video yang dibuat kelas A. Terjadi tanya jawab antara siswa kelas A dengan siswa kelas B dan antara guru dengan kelas A dan B; (5) Selama proses pembelajaran dilakukan pengamatan guru terhadap keaktifan masing-masing siswa.

Situasi belajar secara efektif dan nyaman dalam kelas online yaitu dimana situasi yang kondusif. Hal demikian peserta didik tertantang akan bertanya, mengerjakan tugas, mengungkapkan ide, serta menanggapai sesuatu karena mereka merasa aman dan nyaman serta tidak takut salah (informan NJ, wawancara 1 Januari 2020).

Model pembelajaran cooperative learning mampu menciptakan lingkungan kondusif untuk pembelajaran. Sebab di dalam cooperative learning peserta didik dapat bekerja sama dalam kelompok untuk belajar dan bertanggung jawab akan keberhasilan belajar semua anggota kelompok (Trimurtini, 2009). Penggunaan media digital (gadget) untuk memvideo/ membuat film oleh siswa cukup efektif, karena siswa selama ini penggunaannya dalam hal yang tidak bermanfaat seperti bermain game video dan virtual game lainnya akan lebih baiknya dipakai dalam menyelesaikan tugas pendidikan. Sehingga siswa terlatih dalam kemampuan (skill) berproses dan pengembangan karakter menjadi warga negara Indonesia yang baik (informan FK, wawancara 1 Januari 2020). Penggunaan M-Learning pada gadget untuk mendukung kegiatan pembelajaran siswa sang guru membuat sebuah digital (gadget) aplikasi pendidikan yang melibatkan guru, siswa, dan orang tua. Penggunaan digital (gadget) dalam kegiatan pembelajaran berfungsi sebagai alat pendidikan, sarana evaluasi dan sarana informasi. Hambatan di lapangan mendapati bahwa tidak semua siswa secara aktif berperan serta dalam memprioritaskan sebagai pembelajaran.

\section{Kesimpulan}

Kurikulum merupakan rancangan pendidikan yang merangkum semua pengalaman belajar yang disediakan bagi siswa di sekolah. Dalam kurikulum itu terintegrasi beberapa diantaranya filsafat, nilai-nilai karakter, pengetahuan, dan perbuatan pendidikan serta keterampilan (skill). Generasi millenial yang identik dengan maraknya penggunaan internet sebagai teknologi informasi yang tak terpisahkan dari gadget. Namun penggunaanya masih belum optimal dan kurang dirasakan kebermanfaatannya. Pengembangan kurikulum Pkn di era generasi millenial siswa SMA NU Palangka Raya dengan model cooperative learning lebih efektif dan kondusif dengan berbantuan $M$ Learning (Mobile Learning) pada gadget untuk membuat video/ film. Sebab siswa/ peserta didik dapat bekerja sama dalam kelompok untuk belajar dan bertanggung jawab akan keberhasilan belajar semua anggota kelompok. Siswa terlatih dalam kemampuan (skill) berproses dan pengembangan karakter serta menjadi warga negara Indonesia yang baik. Hasilnya memperlihatkan kegiatan pembelajaran menggunakan digital (gadget) berfungsi sebagai alat pendidikan, sarana evaluasi dan sarana informasi. Hambatan di lapangan mendapati bahwa tidak semua siswa secara aktif berperan serta dalam memprioritaskan sebagai pembelajaran. Diharapkan M-Learning (Mobile Learning) pada media digital dapat diterapkan untuk membantu guru dalam mengatasi kondisi siswa yang memiliki kemampuan bervariasi, jumlah siswa terlalu banyak dan padatnya materi pembelajaran yang harus diselesaikan. Siswa tidak cepat bosan karena dapat menonton video/ film 
keindonesiaan yang dibuatnya bernilai karakter.

\section{Ucapan Terimakasih}

Penulis sangat menghargai Hj. Yuyun Kurniasih, S.Pd sebagai Kepala SMA NU Palangka Raya untuk memberikan izin melakukan penelitian. Kemudian, terima kasih atas bimbingannya yang telah memberikan motivasi kepada penulis untuk segera menyelesaikan penelitian ini

\section{Daftar Pustaka}

Cao, Y., Postareff, L., Lindblom-Ylänne, S., \& Toom, A. (2019). Teacher educators' approaches to teaching and connections with their perceptions of the closeness of their research and teaching. Teaching and Teacher Education. https://doi.org/10.1016/j.tate.2019.06.013

Cheon, J., Lee, S., Crooks, S. M., \& Song, J. (2012). An investigation of mobile learning readiness in higher education based on the theory of planned behavior. Computers $\mathcal{E}$ Education. 59(3), 1054-1064. 5. https:// doi.org/10.1016/j.compedu.2012.04.01

Dryden, G \& Vos, J. (2001). Revolusi cara belajar. Mizan Media Utama (MMU).

Emi, M. (2015). Budaya Baca di Era Digital. Lembaga Ladang Kata.

Farkas, W. A. (2015). Designing, implementing, and evaluating a middle school English language arts program: A mixed methods approach. (Doctoral dissertation, Oakland University).

Hasanudin, A. (2014). Generasi Millennial Indonesia: Tantangan Dan Peluang Pemuda Indonesia. https://doi.org/Alvara Research Center

Ihsan, F. (2015). Dasar-dasar Kependidikan. PT Asdi Mahasatya.

Ioannou-Georgiou, S. (2011). Transition into CLIL: Guidelines for the beginning stages of CLIL. Guidelines for CLIL implementation in Primary and Pre-primary Education. 34-38.

Katz, J. (2012). (2012). Teaching to diversity: The three-block model of universal design for learning. Portage \& Main Press.

Kemendikbud. (2016). Panduan Gerakan Literasi Sekolah. Dirjen Dikdasmen Kemendikbud RI.

Lestari, P. dan S. (2016). Membangun Karakter Siswa Melalui Kegiatan Intrakurikuler, Ekstrakurikuler dan Hidden Curriculum di SD Budi Mulia Dua Pandeansari Yogyakarta. Jurnal Penelitian, Volume 10.

Lion, E. dan H. Y. B. (2013). Metodologi Penelitian Kualitatif. Jenggala Pustaka Utama.

Marttila, K. L. (2017). Determining the Effectiveness of the Saxon Math Program and the Ready Common Core Program for Students with Disabilities. In ProQuest LLC. 
Moser, A., \& Korstjens, I. (2018). Series: Practical guidance to qualitative research. Part 3: Sampling, data collection and analysis. European Journal of General Practice. https://doi.org/https://doi.org/10.1080/13814788.2017.1375091

Naisbitt, J. E. A. (2002). High Tech High Touch. Pustaka Mizan.

Petrova, A., \& Podzygun, O. (2018). Implementation of information and communication technologies in teaching a foreign language for professional communication. Professional competency of modern specialist: means of formation, development and improvement. 163176.

Saefulloh, A. (2018). Peran Pendidik Dalam Penerapan Internet Sehat Menurut Islam. AlTadzkiyyah: Jurnal Pendidikan Islam. https://doi.org/10.24042/atjpi.v9i1.2709

Savarin, W.J and Tankard, J. W. (2005). Communication Thories, methods E Uses in The Massa.

Simonson, M. (2016). Annual Proceedings of Selected Research and Development Papers Presented at the Annual Convention of the Association for Educational Communications and Technology (39th, Las Vegas, Nevada, 2016). Volume 1. The Annual Convention of the Association for Educational Communications and Technology (39th, Las Vegas, Nevada, 2016).

Suyadi. (2015). Strategi Pembelajaran Pendidikan Karakter (Cetakan ke, p. hlm. 61-79). PT Remaja Rosdakarya.

Tapscott, D. (2013). Grown Up Digital: Yang Muda Yang Mengubah Dunia. . Penerjemah: Fajarianto.2013. Jakarta

Trimurtini. (2009). Implementasi Model Cooperative Learning Berbantuan Komputer dalam Pembelajaran Pendidikan Matematika I Pada Mahasiswa PGSD. Jurnal Kependidikan, Vol.39(No.2), hlm.119-126.

Wahab dan Sapriya. (2011). Teori dan Landasan Pendidikan Kewarganegaraan. Alfabeta.

Wahana, H. D. (2015). Pengaruh Nilai-Nilai Budaya Generasi Millennial dan Budaya Sekolah Terhadap Ketahanan Indivdu (Studi di SMA Negeri 39, Cijantng, Jakarta). Jurnal Ketahanan Nasional, Vol.9, XXI, hlm. 14-22,.

Wiedarti, P. (2016). Desain untuk Gerakan Literasi Sekolah. Kemendikbud.

Wuryan dan Syaifullah. (2008). Civics: Ilmu Kewarganegaraan (p. hlm. 9). Laboratorium Pendidikan Kewarganegaraan UPI.

Zuhal. (2000). Visi Iptek Memasuki Millenium III. Universitas Indonesia (UI-Press).

Zuhra, W. U. N. (2017). Kontras Dua Generasi: Millenial Versus Baby Boomer. https://tirto.id/kontras-dua-generasi-millenial-versus-baby-boomer-crCf 